\section{Nuevas notas a propósito de la Galería de Teatro Infantil de Antonio Vanegas Arroyo}

\author{
ALEJANDRO ORTIZ BULLÉ GOYRI \\ Universidad Autónoma Metropolitana-Azcapotzalco
}

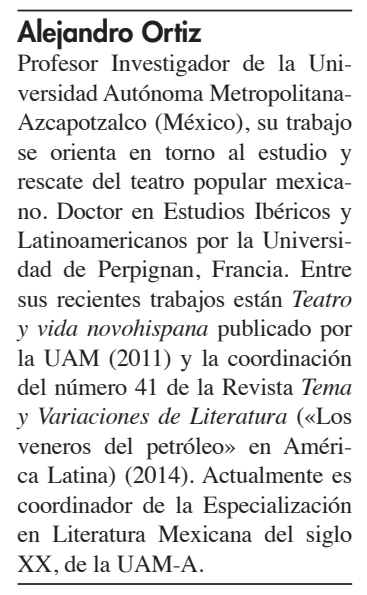

Profesor Investigador de la Universidad Autónoma MetropolitanaAzcapotzalco (México), su trabajo se orienta en torno al estudio y rescate del teatro popular mexicasus recientes trabajos están Teatro la UAM (2011) y la coordinación del número 41 de la Revista Tema y Variaciones de Literatura («Los Amérien Literatura Mexicana del siglo $\mathrm{XX}$, de la UAM-A

\title{
RESUMEN
}

Se trata de un acercamiento a la literatura dramática para niños escrita e impresa por el editor Antonio Vanegas Arroyo en las primeras décadas del siglo XX, Tanto la estructura como la temáticas de los llamados «juguetes cómicos» de Vanegas Arroyo destacan por su originalidad que salen del canon propio de lo que se considera teatro infantil y por su enorme presencia en la niñez mexicana de la época.

Palabras clave: Literatura dramática, Antonio Vanegas Arroyo, Galería de Teatro Infantil.

\section{ABSTRACT}

It is an approach to dramatic literature written and printed for children by Antonio Vanegas Arroyo editor in the early twentieth century, both the structure and the themes of so-called «juguetes comicos», Vanegas Arroyo noted for their originality salt the own canon of what is considered children's theater and its huge presence in Mexican children of the time.

Keywords: Dramatic Literature, Antonio Vanegas Arroyo, Galería de Teatro Infantil.

A lo largo de los distintos estudios, enfoques y perspectivas críticas se ha valorado de manera sobresaliente la labor y las contribuciones del grabador José Guadalupe Posada al amplio espectro de la cultura popular mexicana del siglo xx. Sus célebres calaveras, la Coronela y la Catrina, son figuras icónicas de la imagen que el país tiene de sí mismo. Pero la obra de Posada como grabador no puede entenderse por sí misma, sino por el trabajo conjunto realizado en la imprenta del impresor Antonio Vanegas Arroyo. Y curiosamente la gran mayoría de los grabados de Posada ilustraban gráficamente versos, letras de canciones, corridos, cartas de amor, cuentos, obras de teatro e infinidad de material de impresos y folletería. En el presente trabajo dedicaremos un espacio para acercarnos a la vida y obra de este impresor, cuya obra con la pluma no sólo fue abundantísima y variada, sino que influyó de manera decisiva a la literatura y la cultura mexicana desde finales del siglo XIX hasta nuestros días.

Muchos de los grandes y reconocidos hacedores del teatro mexicano, unos nacidos en los albores del siglo $\mathrm{xx}$, otros unos decenios después, iniciaron su vida teatral en edades muy tempranas, pero no propiamente como "partiquinos», o como meritorios en los montajes de las compañías teatrales de las grandes divas como María Tereza Montoya, ni después de haber tomado cursos de Declamación en el Conservatorio de Música, sino a través de un artefacto hermosísimo hecho de madera y cartón conocido como teatro de títeres, que se vendía en jugueterías en las que representaban obras teatrales de diversa índole, como sainetes, juguetes cómicos, dramas románticos,

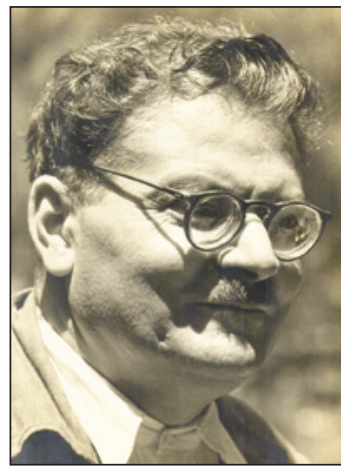

José Guadalupe Posada. 
El Don Juan Tenorio de José Zorrilla fue editado y profusamente difundido también por la imprenta de Vanegas Arroyo.
Nuevas notas a propósito de la Galería de Teatro Infantil de Antonio Vanegas Arroyo

ALEJANDRO ORTIZ BULLÉ GOYRI piezas para teatro infantil y hasta zarzuelas, cuyos libretos se adquirían en cuadernos y hojas sueltas editados principalmente por el impresor y editor Antonio Vanegas Arroyo. Lo que hoy se ha dado en llamar literatura de cordel, por la manera en que se expendían esos textos en las calles y avenidas de las ciudades. En los recuerdos y memorias de Rodolfo Usigli, Salvador Novo, Celestino Gorostiza y hasta del propio Alfonso Reyes, el jugar a los títeres marcó de manera definitoria su vocación literaria y también, en sus respectivos casos, en su carrera en el arte escénico.

Rodolfo Usigli, sin lugar a dudas el dramaturgo mexicano de mayor importancia, en Teatro completo menciona la influencia de las obras para teatro infantil y de muñecos que Antonio Vanegas Arroyo publicó en su imprenta, con ilustraciones de grabadores de la talla de José Guadalupe Posada y Manuel Manilla:

Toda mi infancia hasta los doce años... hice teatro de títeres recorriendo desde los celos de don Folías hasta El casamiento de indios el repertorio íntegro de Vanegas Arroyo. A los siete u ocho me aprendí fiel y puntualmente de memoria, con acotaciones y todo, los siete actos de Don Juan Tenorio ${ }^{1}$ (Usigli 281-282).

En el mismo sentido de las influencias vocacionales que tuvieron los impresos salidos del taller de Vanegas Arroyo en otros intelectuales mexicanos del siglo xx, citemos aquí por su importancia el testimonio del propio Alfonso Reyes al respecto:

Siendo niño, se me ocurrió una vez, llevado de mi naciente pasión por el teatro, fabricar yo mismo unos títeres. Pero cuando después de hacer los muñecos y el escenario, y de escribir las comedias, presenté triunfalmente mi obra a mis hermanos y a mis amiguitos, ellos... jno quisieron jugar! Aquel fracaso me produjo una desilusión tan cruel, que en él suelo ver el origen de mi melancolía, y a él suelo achacar la responsabilidad de cuantas cosas tristes me suceden en la vida.

Sí, cada vez que me ocurre algo desagradable resurge en mí la amargura de aquel recuerdo infantil, y me repito, casi inconscientemente, una frase que a través de los años me persigue como una obsesión: «iMe quedé a solas con mi teatrito!» (Reyes, 1987: 27)

Cabe hacer énfasis en que el testimonio de don Alfonso Reyes, no es otra cosa sino la muestra clara de cómo el teatro de muñecos y los obras dramáticas que publicaba con su imprenta Antonio Vanegas Arroyo y su equipo de escritores e impresores tuvo una importancia crucial en la formación teatral y literaria de una parte sustantiva de la niñez mexicana en las primeras décadas del siglo XX en México. Por ello, vale la pena preguntarnos: ¿qué repertorios contaban los niños de hace un siglo y unas décadas después, para jugar a los títeres? Estaba desde luego la versión reducida para títeres del Don Juan Tenorio de Zorrilla que menciona Usigli en su testimonio, y quizás algunas obras de carácter patriótico, religioso o de veneración a la madre. Pero lo que mayor presencia tuvo en ese jugar a los títeres era la literatura «de cordel» orientada de manera específica a los teatrinos con los que multitud de niños de distintas condición social se entretenían en sus casa, mientras la lluvia les impedía salir a retozar a los patios y jardines o a la calle misma. El gran maestro de esa literatura de cordel fue Antonio Vanegas Arroyo, quien desde su taller de grabador impresor o con el apoyo de las hábiles manos de José Guadalupe Posada como ilustrador, inundó las a los hogares y escuelas del país con obras que pudieran ejecutarse ya fuese con actores aficionados o con muñecos, que, enmuchas ocasiones, eran hechos con un pedazo de tela y una cabecilla de barro pintada con simples rasgos pero con la disposición a ser encantados con la imaginación de los titiriteros de la infancia. Pero no sólo Vanegas Arroyo desarrolló hace más de un siglo un repertorio de obras para teatro de muñecos. De hecho hay una añeja tradición de literatura popular para títeres que vale la pena revisar. Por lo menos en cuanto a sus autores o a las circunstancias en que se escribieron, como fue el caso de las compañías de teatro de muñecos que deambulaban por los caminos de la Nueva España al menos a lo largo del siglo Xvin y de la que necesariamente desciende la tradición del títere popular mexicano y del teatro infantil de principios del siglo xx.

¿Pero quién fue Vanegas Arroyo? ¿Fue tan sólo el dueño de la imprenta de donde salieron las celebérrimas ilustraciones de José Guadalupe Posada?

Hagamos un ligero apunte biográfico de este empresario grabador, que hasta donde sabemos fue también autor de muchas de las piezas teatrales que salían de sus talleres con ilustraciones de Posada. 
Antonio Vanegas Arroyo, es reconocido primeramente como impresor, pero también como «autor de sainetes de costumbres» - quizá por el sentido inclasificable que pudiera tener su labor de impulsor de la dramaturgia popular de su tiempo-. De hecho su impreso más famoso, no es propiamente, ni el de una obra teatral ni el de la Calavera Catrina de José Guadalupe Posada; sino el folleto conocido como Nueve jornadas de los Santos Peregrinos que contiene las letanías para «Pedir Posada» que aún en la actualidad se sigue utilizando en México en las fiestas navideñas.

Se calcula que fue autor reconocido de treinta y seis pequeñas obras breves de las cuales podrían reconocerse de su autoría textos como Perico el incorregible, Casa de Vecindad, Celos del negro con don Folías, entre otras más con las que transitó por diversos géneros de teatro popular, como pastorelas, sainetes infantiles y obritas de carácter cívico religioso con un sentido festivo o conmemorativo, y que se constituyeron en su "Galería de teatro para niños». La leyenda en torno a su labor dramatúrgica establece que por lo general sus obras aparecieron publicadas como anónimas pero que él mismo las escribía o creaba el argumento y que un poeta oaxaqueño llamado Constancio S. Suárez, autor de muchos de los corridos y versificaciones de noticias y acontecimientos que ilustraba también Posada, las configuraba en la forma en que se llegaban a imprimir. Si esto fue cierto, la autoría sería de ambos: Vanegas Arroyo-Constantino Suárez, como ocurrió en infinidad de ocasiones con los autores de los libretos para el teatro de revista. Así, podemos afirmar que buena parte del repertorio teatral del período de entresiglos (18901918 ca.) era editado por Vanegas Arroyo en impresiones populares que eran adquiridas, no precisamente por compañías dramáticas profesionales, sino por cuadros de aficionados y por niños que solían representar dramas, juguetes cómicos y zarzuelas en ambientes familiares o en tertulias artístico literarias. Como se puede observar en el siguiente texto con que se anuncian las obras publicadas por la Casa Vanegas Arroyo y resulta un interesante testimonio de la amplitud del repertorio que salía de sus imprentas:

¡lmportante, ilmportante!! A los aficionados al teatro. / Por veinte centavos / puede usted hacerse
/ de un bonito libreto / de la zarzuela que más le agrade entre las siguientes: / El de la virjen milagro, Chatean Margaux, Manicomio de cuerdos, Las tentaciones de san Antonio, El cura de Jalatlaco, El hombre es débil, La gallina ciega, Niña Pancha. / Libretos de a 10 centavos cada uno: Luz y sombra y Toros de puntas. / De a 50 centavos el ejemplar: La tempestad, El anillo de bierro y El rey que rabió. / El pasado, drama escrito por Manuel Acuña, 20 cvs. La pasionaria, drama de Leopoldo Cano, 50 crs.

Champagne frappé, juguete cómico en un acto, 20 cvs., y otras obras dramáticas mexicanas a precios sumamente módicos. / Monólogos a 6cvs. el ejemplar: Amor que envilece, Antes del baile, Amar sin esperanza, Haciendo el oso, Pasión eterna y Fregolí, que se recomienda por su originalidad. / De venta en la casa editorial de Antonio Vanegas Arroyo (Cit. Por López Casillas, 2003: 62).

También puede rastrearse la presencia de Vanegas Arroyo en otras publicaciones ajenas a su imprenta como La Gaceta callejera, El boletín, El jicote, El teatro, El centavo perdido, y seguramente otras más (Diccionario Porrúa, 1995: 3676).

Se sabe que nació en la ciudad de Puebla en 1852 y que falleció en la ciudad de México en el pleno año del Congreso Constituyente en 1917. Su vida, su labor y su obra de creación y difusión de literatura popular marca no solamente un período en la vida y la cultura mexicana, sino que abrió las puertas para la recuperación del patrimonio cultural al término de la lucha armada, cuando surge lo que el pintor y muralista Jean Charlot dio en llamar «El Renacimiento Mexicano» (Charlot, 2015), cuando entre él y varios otros artistas plásticos, incluido Diego Rivera, recuperaron numerosas placas de impresión de los talleres de Vanegas Arroyo que para los años veinte se encontraban abandonados en un domicilio cercano a la antigua Academia de San Carlos en el Centro Histórico de la ciudad de México.

Antonio Vanegas Arroyo publicó hacia 1905 una serie de relatos para niños fundacio-
Nuevas notas a propósito de la Galería de Teatro Infantil de Antonio Vanegas Arroyo ALEJANDRO ORTIZ BULLÉ GOYRI 
3 2015)].

A propósito de ello, Guadalupe Ríos hace una observación interesante en cuanto a la tradición del grabado mexicano de ilustrar "calaveras» y de lo que salía del taller de Vanegas Arroyo con esa temática: "Algunos estudiosos del tema coinciden en que los artistas Constantino Escalante (1836-1868) y Santiago Hernández (1833-1908) fueron los primeros en litografiar figuras de calaveras, representaciones hechas con un enfoque y crítica de tipo político en el bisemanario La Orquesta. Sin embargo, se ha considerado a Manuel Manilla el primer caricaturista que grabó calaveras; éstas después habrían de alcanzar su plenitud con José Guadalupe Posada al enfatizar en ellas la vida costumbrista del siglo pasado y principios del XX así como al personificarlas como seres altamente conocidos de la época». (Ríos de la Torre, 2007 107-119).

Acuerdo núm. 64 por el que se declara monumento histórico el inmueble ubicado en el número 27 de la calle Penitenciaría en la Colonia Penitenciaría, de la ciudad de México, D. F., [http://sep.gob.mx/ work/models/sepl/Resource/ d3c9731a-2b58-4778-a9c9 ecla7021 eb34/a64.pdf, (mayo

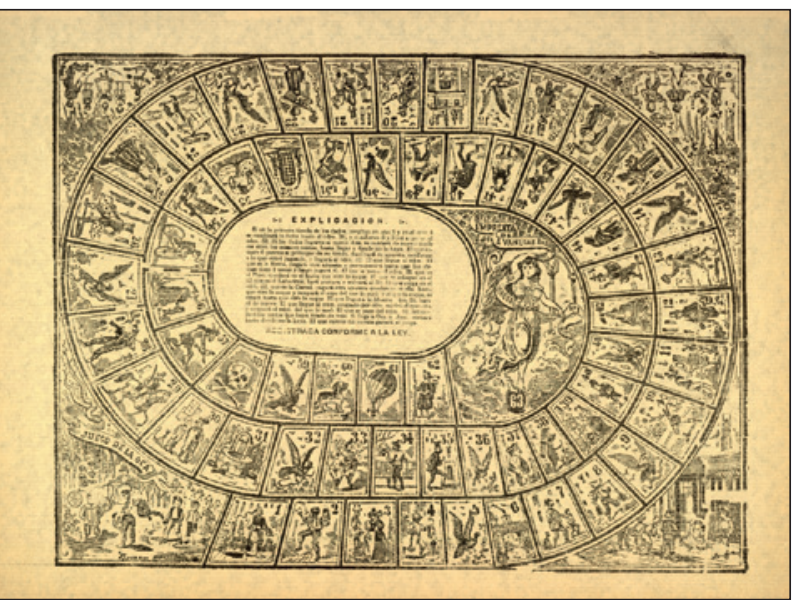

Juego de la oca, José Guadalupe Posada, imprenta Vanegas. nales en la historia de la literatura para niños en el siglo xx: El doctor improvisado, Juan Ceni$z a$, La niña de las perlas, y La viejecita dichosa, con grabados de J. G. Posada y M. Manilla que años después reeditaría la SEP en su colección «Libros del Rincón» (Pereira-Albarrán, 2004: 297) Sus obras teatrales, conocidas como «juguetes cómicos», se siguieron representando en los años cincuenta y sesenta del siglo $\mathrm{xx}$, con grupos de teatro como el Teatro Estudiantil Autónomo bajo la dirección de Xavier Rojas y el Teatro Trashumante del INBA bajo la dirección de Óscar Chávez.

En un principio la Casa Vanegas Arroyo funcionó hacia 1880 como encuadernadora, pero ante la demanda de clientes fue transformándose en una casa impresora de folletería y hojas sueltas hasta llegar a ser una casa editora de libros y cuadernillos. Junto con Antonio Vanegas Arroyo trabajaba un equipo de impresores, grabadores como los citados Manuel Manilla y José Guadalupe Posada y muchos otros artistas populares que con certeza pasaron por sus talleres ${ }^{1}$ y escritores como el ya citado Constancio S. Suárez, así como Arturo Espinoza Chóforo Vico, Francisco Osacar, y Ramón N. Franco (Castro Pérez, 2013: 491503) y miembros de su propia familia como su hijo Blas. El taller de la Imprenta Vanegas Arroyo se encontraba en la calle de Penitenciaría número 27 en la ciudad de México, y el inmueble fue declarado monumento nacional en

$1982^{2}$. Su nieto Arscacio Vanegas en los años cincuenta colaboró en el entrenamiento del grupo de revolucionarios cubanos encabezados por Fidel Castro durante su estadía en México y al parecer, las imprentas de la Casa Vanegas Arroyo todavía imprimieron algún tipo de material editorial para la causa revolucionaria cubana, (Castro Pérez, 2013: 492).

De la Casa Vanegas Arroyo salieron a la luz Nuevas notas a propósito de
la Galería de Teatro Infantil de Antonio Vanegas Arroyo ALEJANDRO ORTIZ BULLÉ GOYRI publicaciones periódicas como La Gaceta callejera, el boletín, El Centavo perdido, el Jicote,

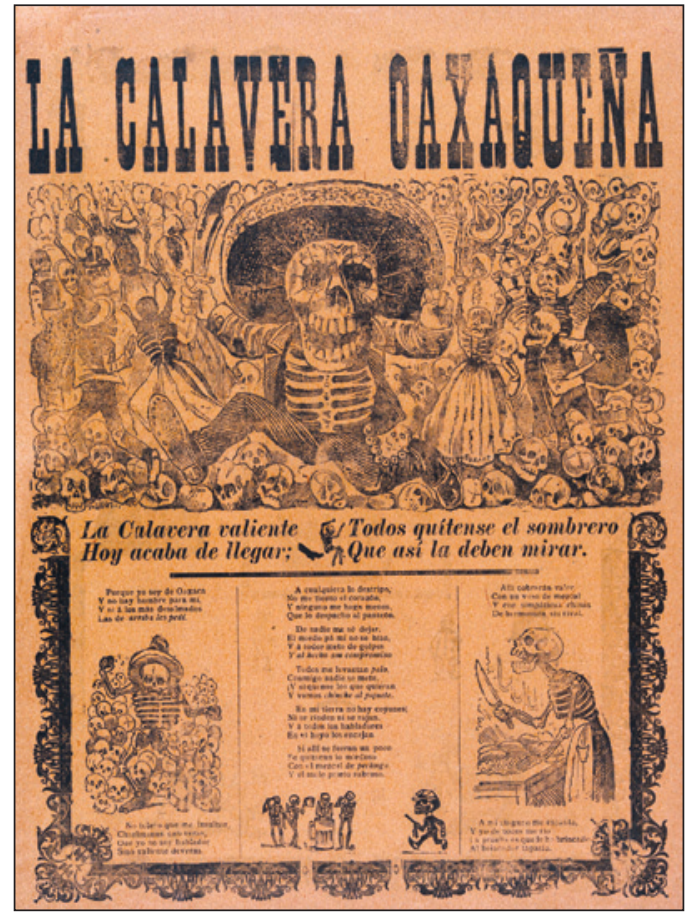

Calavera oaxaqueña, de José Guadalupe Posada.

El Teatro, La Casera, entre otras. Quizá lo que más prestigió le dio con el paso del tiempo a la casa impresora y a sus equipo de grabadores y literatos populares fueron las colecciones de «calaveras literarias» que hacia el mes de noviembre se llegaban a publicar año con año, con los grabados de José Guadalupe Posada y el sello inconfundible de su estilo.

No está claramente establecida la autoría de Antonio Vanegas Arroyo a propósito de los incontables pliegos, hojas sueltas, hojas religiosas, corridos, manuales, obras teatrales, cuentos, poemarios, noticias de crímenes, hojas volantes, folletos y demás que aparecieron en su imprenta. Puede afirmarse a propósito su labor de autor de literatura popular que por lo general sus obras aparecieron publicadas como anónimas pero que él mismo las escribía o creaba el argumento y que el poeta oaxaqueño Constancio S. Suárez, y los otros autores citados arriba colaboraban en los diálogos, textos y versificaciones de noticias y acontecimientos para que posteriormente las ilustraran Manilla o Posada. Si esto fuera cierto, la autoría sería compartida, como ocurrió en infinidad de ocasiones con los autores de los libretos para el teatro de revista en la misma época. Pero sí podría afirmarse que Vanegas Arroyo escribía algunas de los textos que se publicaban. 
En el Fondo Reservado de la Biblioteca Nacional de México, se encuentra un repertorio valioso para quien desee adentrarse en el estudio particular de la obra de Antonio Vanegas Arroyo y su taller de grabado. A continuación presentamos un sucinto listado de algunas de las obras impresas más importantes atribuidas a Antonio Vanegas Arroyo, entre las que cabe destacar los cuentos para niños, los cancioneros y, desde luego, los llamados «juguetes cómicos» para ser representados por niños o por títeres, junto con los versos de las llamadas «Posadas Navideñas» Nueve Jornadas de los santos Peregrinos, con su respectiva obra para ser representada $L a$ Aurora del nuevo día en los campos de Belem, (pastorela en un acto).

\section{Nueve Jornadas de los santos Peregrinos}

La Aurora del nuevo día en los campos de Belem, (pastorela en un acto). S.f.

El clown mexicano

Coloquio para celebrar las cuatro apariciones de la virgen de Guadalupe

Galería de teatro infantil, colección de comedias para teatro infantil o de titeres (Los celos del negro con don Folías, Los sustos del valedor, El casamiento fustrado [sic], Perico el incorregible, Por fingir espanto, Casa de vecindad, Una corrida de toros o el amor de Luisa, La almoneda del diablo, El consultorio médico, entre otras muchas)

Elplacer de la niñez, colección de monólogos.

Magia blanca y magia prieta

El secretario de los amantes (recopilación de cartas de amor)

Bonita colección de cuentos para los niños (El doctor improvisado, Juan Ceniza, La niña de las perlas, y La viejecita dichosa).

Nueva colección de canciones modernas para el presente año (1909) [que probablemente algunas fueron de su autoría y que publicó y antologó a lo largo de distintos años durante el porfiriato (1876-1911)].

Todo este material, al que se añaden las famosas «calaveras», «versos» «corridos» «noticias» y demás impresos de cuadernillos, impresos y hojas sueltas es abundantísimo, se encuentra disperso tanto en colecciones particulares como en distintas bibliotecas y fondos documentales no sólo en México sino sobre todo en universidades norteamericanas que han llegado incluso a digitalizar un número interesante de documentos como grabados, volantes y hojas sueltas, y que puede con- sultarse en línea. Incluso, el Centro Nacional de Investigación Teatral «Rodolfo Usigli» de México, en una edición de discos compactos con materiales diversos y documentos sobre las legendarias compañía de títeres y autómatas de los Hermanos Rosete Aranda y de Carlos Espinal, transcribe algunas de las obras del repertorio de estas compañías, entre las que aparecen algunas de las que el mismo Antonio Vanegas Arroyo editó en su taller de impresión, (Giménez Cacho-Miranda, 2010).

En relación con las obras para teatro infantil y de muñecos de autoría de Antonio Vanegas Arroyo y sus colaboradores, el investigador John B. Nomland, que las conoció y

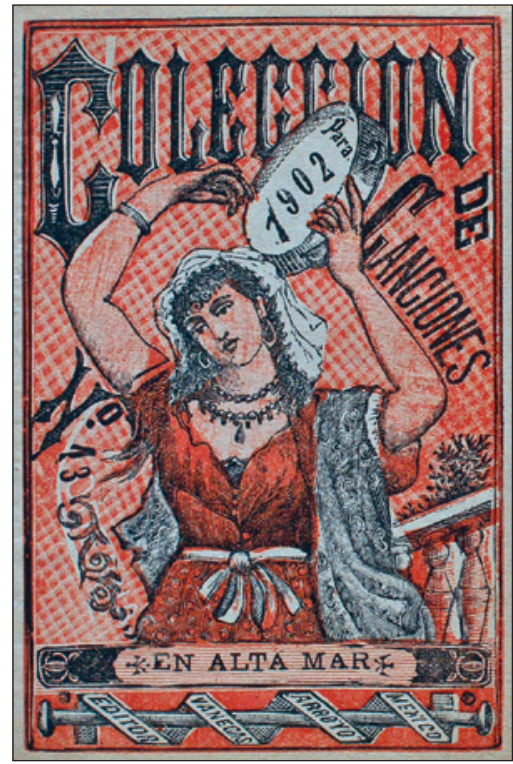

Cancionero. estudió con genuino interés, pudo establecer estas observaciones:

Una lectura de las series nos revela tres tipos básicos de obras: El juguete cómico, la comedia y la comedia de magia. Las más numerosas y de mayor interés son los juguetes cómicos, sorprendentes y en ocasiones desconcertantes, plagados de placer, celos, infidelidades, asesinatos, embriaguez y golpes. Escritas generalmente en un acto en una mezcla de prosa y verso, son más que otra cosa pequeñas viñetas de personajes (empobrecidos social y económicamente) del ambiente local (Nomland, 1965: 75).

En efecto, una lectura contemporánea de estas obras nos hace ver que su escritura estaba muy cercana a la estética propia de los corridos y de las hojas sueltas que se elaboraban en la Casa Vanegas Arroyo. Incluso tiene una extraña semejanza con el teatro de revista al presentar personajes típicos en escenas y ambientes populares, y que sin duda continúa una tradición desarrollada a través del sainete novohispano. En ocasiones, como en Los celos del negro con don Folías, uno de los «juguetes cómicos» más célebres, estaban más cerca de la crónica de nota roja, con la salvedad de que se trataba de textos elaborados no sólo para su lectura, sino para su representación y por añadidura para ser realizada por niños o para niños. Es decir, la noción de moralidad social y familiar queda muy alejada de lo que podría imaginarse desde nuestra perspectiva

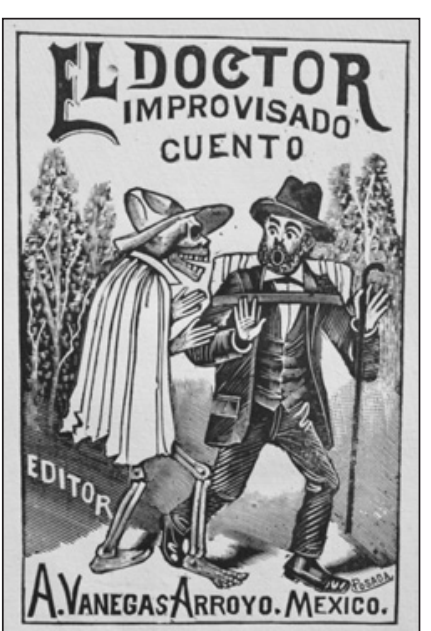

El doctor improvisado.

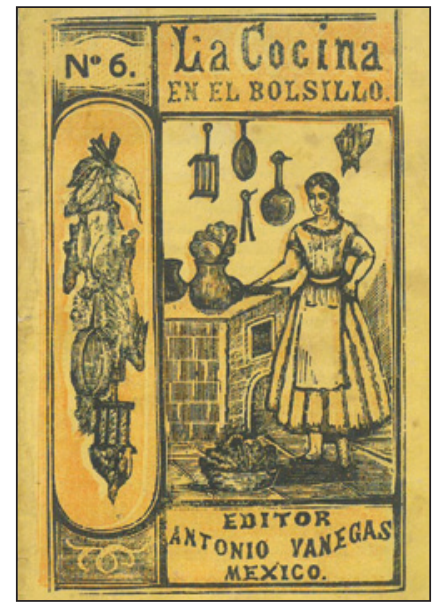

La cocina en el bolsillo.

Nuevas notas a propósito de la Galería de Teatro Infantil de Antonio Vanegas Arroyo

ALEJANDRO ORTIZ BULLÉ GOYRI 


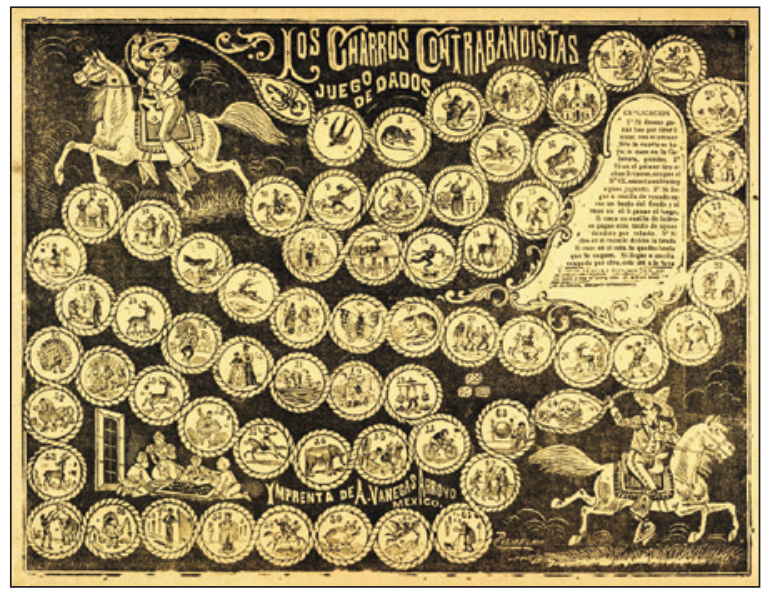

Juego de dados.

4

Vanegas Arroyo la titula así, de manera más amplia: «Perico el incorregible, Juguete cómico en un acto. TEATRO INFANTIL, colección de comedias para representarse por niños o por títeres».

\section{ESCENA PRIMERA}

Nuevas notas a propósito de la Galería de Teatro Infantil de Antonio Vanegas Arroyo ALEJANDRO ORTIZ BULLÉ GOYRI de lo que fueron la literatura y el teatro populares durante el porfiriato.

Perico el incorregible $^{4}$, por ejemplo (Giménez Cacho-Miranda, 2010) es lo que podría llamarse un juguete cómico, en donde más allá del desarrollo de una trama o de presentar trayectorias de personajes, nos presenta el autor, cuadros de costumbres populares, con un cierto afán moralizante con un espíritu risueño. Perico es un personaje popular urbano, que con su pregón vendedor de diarios en la ciudad:

Perico paseándose de acera a acera. Fingiéndose el borracho y con un montón de papeles desordenados en la mano.

¡Ay! qué suerte tan chaparra,

No la he conocido igual;

No la tiene ni el Tortuga

Con sus alas de petate

Y sus ojos de cristal.

Por más que me desgañito

Y grito con voz ufana,

El Gil Blas de mañana

El Fandango, Don Tepito,

Cuanto se me da la gana.

La espantosa noticia

Del que á su madre mató

Y luego se la comió

Con la mayor injusticia

El milagro portentoso

De Señor San Expedito,

Que lo cantó á todo grito

Por ser Santo milagroso.

El Fandango, la Casera,

El Monitor Republicano

Y cuanto llevó en la mano

$\mathrm{Y}$ en mi pobre faltriquera.

\section{ESCENA SEGUNDA}

Perico y el Gendarme que llega muy quedo á colocarse tras de Perico.

Perico Los versos del agiotista Las gracias del tecolote
Con su pistola y garrote....

¡Ah!, si lo tengo á la vista!

Gen. (Afianzándolo del pescuezo.)

¿Qué es lo que dices menguado?

Perico Nada, Siñor,

Los versos de Don Quijote....

Gen. Marche, pues, el hablador;

Zas, vamos á la Inspección.

Allí le darán tecolote,

¡Que es una buena ración!

Perico Pero, Siñor Don Germán,

Yo nada he dicho en defeuto

De la persona de usté

$\mathrm{Ni}$ tampoco estoy trompeto.

Gen. Por la última le perdono,

Váyase pronto de aquí,

Y agradézcamelo á mi

Que yo le tengo incono

(Se va el gendarme)

Después de esta curiosa primera escena en que Perico consigue, por suerte, liberarse de ser llevado a prisión por el gendarme por razones no precisas, le suceden un par de escenitas en que Perico "el incorregible» se embriaga en una comilona y se arma gran escándalo. Aparece de nuevo la autoridad para llevárselos a la cárcel, por escandalizar pero Perico logra de nuevo burlar a la prisión y la obrita culmina con unos versitos de Perico dirigidos al público espectador:

Si este juguete te agrada

Sólo una cosa suplico,

Que le des una palmada

Al autor y á Perico (Giménez Cacho-Miranda, 2010).

Estas expresiones de sainete popular, resultan un ejemplo claro de lo que solían ser las obras publicadas por Vanegas Arroyo: brevísimos textos dramáticos, aptos para ser representador por infantes ya fuese en sus teatrino con títeres o por ellos mismos en sus casas, en un ambiente de juego o de fiesta. Y en medio del tono risueño e ingenuo de las obras, con personajes y lenguaje popular solía mostrarse algún aspecto moralizante. En este caso a propósito de los efectos negativos del consumo de bebidas embriagantes. 
Otro ejemplo de los más singulares es el que líneas arriba se mencionó: Los celos del negro con Don Folías, por tratarse de un texto en verso escrito para ser escenificado, pero que se aleja de lo que podría esperarse de un teatro para niños, en virtud de que representa las maquinaciones de un hombre celoso para asesinar a un individuo. Una suerte de representación escénica «para niños» de nota roja periodística, que ya desde el monólogo inicial del personaje del Negro se aprecia con claridad:

$\begin{array}{ll}\text { NEGRO } & \text { Hoy quiero desengañarme } \\ \text { Si me es infiel mi mujer } \\ \text { Si la veo con Don Folías } \\ \text { Ya se puede componer, } \\ \text { A los dos los he de hacer } \\ \text { Tasajos con mi cuchillo. } \\ \text { Porque yo no soy mocoso } \\ \text { Ya tengo duro el colmillo; } \\ \text { Y si hablandose los pillos } \\ \text { Que se cuenten con los muertos, } \\ \text { Pues los celos que padezco } \\ \text { Me harán hacer desaciertos, } \\ \text { Hay dichos que salen ciertos } \\ \text { Y recuerdo con dolor } \\ \text { Que hay uno que dice así: } \\ \text { «El más amigo es traidor.» } \\ \text { Pero alguno aquí se acerca } \\ \text { (Volteando la cara.) } \\ \text { (Se esconde) (Don Folías va saliendo) } \\ \text { (Giménez Cacho-Miranda, 2010). }\end{array}$

Es factible pensar que esta obrita, como muchas otras hayan pertenecido al dominio popular y que provengan de muy variadas fuentes de la tradición escénica. El acierto de Vanegas Arroyo fue el de haberles dado una forma asequible para su distribución en forma de cuadernillos y hojas sueltas en su llamada Colección de obras para niños y títeres a la que genéricamente le titulaba «Galería del teatro infantil».

Los juguetes cómicos, los monólogos, junto con los versitos, y las distintas colecciones de cuentos y toda la suerte de escritos destinados al público infantil y publicados por la Casa impresora y editorial de Antonio Vanegas Arroyo fue cobrando una fama legendaria, no tanto por su contenido sino por la estética de los grabados con que se ilustraban las ediciones, a cargo como bien se sabe de José Guadalupe Posada y Manuel Manilla entre otros grandes grabadores populares.
Pero es justo mencionar aquí, que los textos mismos constituyen una fuente de gran riqueza para el estudio de la literatura popular en Hispanoamérica y en particular de los textos que se editaban para promover la lectura y la representación teatral entre la población infantil de México en las postrimerías del siglo XIX y en los albores del siglo XX. Falta, claro está, un enorme camino por recorrer, que va desde el acopio y recopilación de los textos mismos, hasta su análisis, interpretación y su futura reimpresión ya fuese en edición crítica o en ediciones facsimilares.

\section{Bibliografía}

Castro Pérez, Briseida. «La imprenta de Vanegas Arroyo camino a la digitalización y acceso público; cuadernillos, hojas volantes y libros». Revista de Literaturas Populares, XIII: 2, (2013): 491-503.

Charlot, Jean. Ensayos sobre arte mexicano. En Jean Charlot [Web](editado por Peter Morse y John Charlot). Recuperado de http://www.jeancharlot.org/writings/ escritos/

Contreras Soto, Eduardo. «Versitos alegres, tonada elegante de Silvestre Revueltas, aspectos históricos y escénicos de El renacuajo paseador». Discanto, (2005): 155-170.

Diccionario Porrúa de Historia, Biografía y Geografía de México, 6a. ed. México: Porrúa, 1995.

Giménez Cacho, Marisa y Miranda, Francisca (eds.). Empresa Nacional de Autómatas Hermanos Rosete Aranda (1835-1942) [CD-ROM]. México: CITRU-INBA/ CONACULTA, 2010.

Espinoza, Tomás. Galería de teatro para niños. México: Instituto Mexicano del Seguro Social, 1988.

Flores Villela, Arturo. México, la cultura, el arte y la vida cotidiana. México: UNAM, Cuadernos del CIIH, serie Fuentes 7, 1990.

Flores, Enrique, reseña a López Casillas, Mercurio, José Guadalupe Posada. Ilustrador de cuadernos populares. México: Editorial RM. en Revista de Literaturas Populares, III:1 (2003): 169-175.

Miranda Ricardo. «Del festín al alboroto: forma y narrativa en El renacuajo paseador de Silvestre Revueltas». Discanto, Xalapa, Universidad Veracruzana, (2005): 171-185. [Recuperado de www.fororevueltas.unam.mx]
Nuevas notas a propósito de la Galería de Teatro Infantil de Antonio Vanegas Arroyo ALEJANDRO ORTIZ BULLÉ GOYRI 
Nomland, John B. Teatro mexicano contemporáneo (1900-1950). México, INBA, 1967.

Pereira, Armando (coord.), Claudia Albarrán, Juan Antonio Rosado, Angélica Tornero (colaboradores). Diccionario de literatura mexicana siglo $X X$. México: UNAM/Ediciones Coyoacán, 2004.

Reyes, Alfonso. "Cuatro preguntas». OC XXII, (Marginalia, Las burlas veras). México: FCE, 1989.

Ríos de la Torre, Guadalupe. «José Guadalupe Posada, un cronista de la época porfiriana». Tema y Variaciones de Literatura, 28, (2007): 107-119.

Speckman Guerra, Elisa. «Cuadernillos, pliegos y hojas sueltas en la imprenta de
Antonio Vanegas Arroyo». La república de las letras: asomos a la cultura escrita del México decimonónico / Edición de Belem Clark de Lara y Elisa Speckman Guerra. México: Universidad Nacional Autónoma de México, Instituto de Investigaciones Históricas, Coordinación de Humanidades, Instituto de Investigaciones Bibliográficas, Instituto de Investigaciones Filológicas, Dirección General de Publicaciones y Fomento Editorial (2005): 391-414.

Usigli, Rodolfo. Teatro Completo, v. III. México: FCE, 1979, pp. 281-282.

Fecha de recepción: 28/07/2015

Fecha de aceptación: 10/12/2015 